\title{
Biofumigação de substratos com espécies amazônicas para produção de mudas de cafeeiro livres do nematoide-das-galhas
}

Na agricultura atual, a busca por estratégias de manejo integrado de doenças deve ser uma busca constante, visando a máxima eficiência produtiva, o menor custos de produção e redução de possiveis impactos ambientais e humanos. Nesse sentido, tem-se buscado por métodos alternativos, que sejam diferentes do controle químico com nematicidas a fim de atender aos princípios que norteiam o manejo integrado. Objetivou-se avaliar a incorporação de folhas de Copaifera sp. e Vismia guianensis, para se determinar seu potencial biofumigante-nematicida contra o nematoides-das-galhas do cafeeiro (Meloidogyne incognita). Os materiais foram divididas em material vegetal seco (60 C por 72 horas) e fresco. Esta incorporação foi feita proporção de 62,5 gramas de material vegetal por litro de solo, aos 15 dias e um dia antes do plantio das mudas de cafeeiro. Foram utilizados como testemunha o nematicida Carbofuran (20 $\mathrm{mL} /$ /litro) e tratamentos sem material vegetal, com e sem inoculação, com seis repetições. Após a ANOVA e teste de média de Scott Knott a $5 \%$, observou-se que, para o número de galhas por grama de raízes destacou o tratamento Copaifera sp. seca e incorporada 15 dias antes em comparação ao nematicida, e para fator de reprodução e número de ovos/grama de raízes se destacou o Vismia guianensis 15 seca e incorporada 15 dias antes em comparação ao carbofuran. Entretanto, observa-se que em todos os casos avaliados com o uso de material incorporado seco ou fresco, houve algum efeito deletério sobre o crescimento das mudas, tanto no sistema radicular quanto na parte aérea das plantas, quando comparados à testemunha não tratada, embor somente no caso de Vismia houve diferença significativa quando comparadas ao controle. Os resultados apresentados demonstram que é possível inibir o patógeno pela incorporação de folhas secas e trituradas de Vismia guianensis no substrato para mudas de cafeeiro, preferencialmente 15 dias antes do plantio.

Palavras-chave: Coffea canéfora; Meloidogyne incógnita; Biofumigação.

\section{Biofumigation of substrates with amazonian species for the production of coffee seedlings free of the gnath nematode}

\begin{abstract}
In current agriculture, the search for integrated disease management strategies should be a constant search, aiming at maximum productive efficiency, lower production costs and reduction of possible environmental and human impacts. In this sense, we have sought alternative methods that are different from chemical control with nematicides in order to meet the principles that guide integrated management. The objective of this study was to evaluate the incorporation of Copaifera sp. and Vismia guianensis, to determine their biofumigant-nematicidal potential against the coffee gnath nematodes (Meloidogyne incognita). The materials were divided in dry plant material (60 C for 72 hours) and fresh. This incorporation was made proportion of 62.5 against the coffee gnath nematodes (Meloidogyne incognita). The materials were divided in dry plant material ( $600 \mathrm{C}$ for 72 hours) and fresh. This incorporation was made proportion of 62.5
grams of plant material per liter of soil, at 15 days and one day before planting the coffee seedlings. Carbofuran nematicide ( $20 \mathrm{~mL} /$ liter) and treatments without plant material, with and without inoculation, with six replicates were used as controls. After the ANOVA and Scott Knott's mean test at $5 \%$, it was observed that, for the number of galls per gram of roots, the Copaifera sp. dry and incorporated 15 days before compared to nematicide, and for reproductive factor and number of eggs / grams of roots was exposed Vismia guianensis 15 dry and incorporated 15 days before compared to carbofuran. However, it is observed that in all cases evaluated with the use of dry or fresh material, there was some deleterious effect on the growth of the seedlings both in the root system and in the aerial part of the plants, when compared to the untreated control, although only in the case of Vismia there was a significant difference when compared to the control. The results show that it is possible to inhibit the pathogen by the incorporation of dry and crushed leaves of Vismia guianensis in the substrate for coffee seedlings, preferably 15 days before planting.
\end{abstract}

Keywords: Coffea canephora; Meloidogyne incognita; Biofumigation.

Topic: Proteção de Plantas e Fitotecnia

Reviewed anonymously in the process of blind peer.
Received: $12 / 02 / 2019$

Approved: 28/03/2019
Elize Francisca Mendes dos Anjos (iD) Universidade Federal de Rondônia, Brasil http://lattes.cnpq.br/4123000737054763 http://orcid.org/0000-0002-5715-0275 elizeanjos@gmail.com

José Roberto Vieira Júnior Embrapa Rondônia, Brasil http://lattes.cnpq.br/9904275274067824 http://orcid.org/0000-0001-7939-8119 jose-roberto.vieira@embrapa.br

Cléberson de Freitas Fernandes Embrapa Agroindústria Tropical, Brasil http://lattes.cnpq.br/7426209328649448 http://orcid.org/0000-0001-5269-1139 cleberson.fernandes@embrapa.br
Rodrigo Barros Rocha

Embrapa Rondônia, Brasil

http://lattes.cnpq.br/8295625748916004

rodrigo.rocha@embrapa.br

Cássya Fonseca Santos (iD

Embrapa Rondônia, Brasil

http://lattes.cnpq.br/7307255387433142

http://orcid.org/0000-0003-3298-7527

casyaf@hotmail.com

Naiara Pires Ramos

Embrapa Rondônia, Brasil

http://lattes.cnpq.br/0864461169748330

naiara.shadows@gmail.com

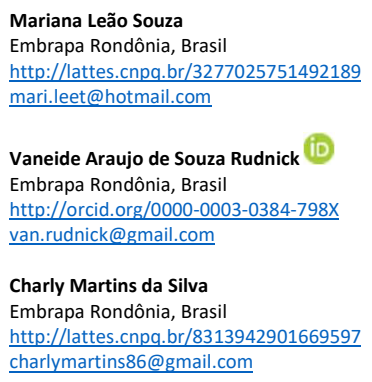

Mariana Leão Souza Embrapa Rondônia, Brasil http://lattes.cnpq.br/3277025751492189 mari.leet@hotmail.com

Vaneide Araujo de Souza Rudnick (D) Embrapa Rondônia, Brasil http://orcid.org/0000-0003-0384-798X van.rudnick@gmail.com

Charly Martins da Silva Embrapa Rondônia, Brasil http://lattes.cnpq.br/8313942901669597 charlymartins86@gmail.com

Solange Aparecida Rodrigues Mariobo Embrapa Rondônia, Brasil http://lattes.cnpq.br/3122215913759040 solangero2012@gmail.com

Gleiciele Ribeiro da Silva (iD) Embrapa Rondônia, Brasil http://lattes.cnpq.br/2903605219047703 http://orcid.org/0000-0002-6078-2230 rbrogleice@outlook.com
Referencing this:

ANJOS, E. F. M.; VIEIRA JÚNIOR, J. R.; FERNANDES, C. F.; ROCHA, R. B.; SANTOS, C. F.; RAMOS, N. P.; SOUZA, M. L.; RUDNICK, V. A. S.; SILVA, C. M.; MARIOBO, S. A. R.; SILVA, G. R.. Biofumigação de substratos com espécies amazônicas para produção de mudas de cafeeiro livres do nematoide-das-galhas. Revista Ibero Americana de Ciências Ambientais, v.10, n.2, p.25-34, 2019. DOI:

http://doi.org/10.6008/CBPC2179-6858.2019.002.0003 


\section{INTRODUÇÃO}

O estado de Rondônia é o segundo maior produtor de Coffea canephora e, de acordo com a CONAB (2018), a produção de café deste ano tem prognóstico de 17 a 24\% superior ao ano de 2017. Porém o fator fitossanitário pode afetar esta estimativa, devido a incidência de nematóides do gênero Meloidogyne em áreas produtoras do estado, o que pode reduzir a produtividade da cultura (VIEIRA JUNIOR et al., 2015).

Estima-se que a redução na produção nacional de café esteja em torno de $20 \%$, devido ao ataque de fitonematoides (OLIVEIRA et al., 2018) Em estudo recente, Almeida et al. (2017) demonstraram que Meloidogyne exigua, estaria parasitando plantas Coffea arábica variedade 'Novo Mundo' e estimaram por geoestatística que este ataque estaria provocando uma redução de $30 \%$ na produtividade do cafeeiro.

E para o controle de fitonematoides, o uso de nematicidas sintéticos é amplamente usado, no tratamento de mudas e em covas no plantio do cafeeiro, entretanto um dos produtos utilizados num passado recente era o Carbofuran, no entanto Hmimou et al. (2014), identificou que este princípio ativo possui grande mobilidade no solo, sendo lixiviado, para profundidades maiores que o sistema radicular das plantas, que é o alvo de ação. Além da contaminação das águas subterrâneas, como foi identificado por Santos et al. (2016), principalmente em solos ácidos. Assim uma das alternativas no controle do Meloidogyne spp., sendo menos tóxica ao homem e ao ambiente, é o uso de espécies vegetais incorporadas ao substrato, conhecida como biofumigação e, ou, adubação verde, técnica a qual diversos autores citam resultados positivos no controle do patógeno, (D’ADDABBO et al., 2017; ESTUPIÑAN-LÓPEZ et al., 2017; HANDISENI et al., 2017).

Além do controle do fitonematoide, o uso de adubação verde é uma alternativa, no manejo do solo em sistemas agroecológicos, garantindo a fertilidade do solo (FARINA et al., 2018). Esse sistema vem sendo utilizado não só em culturas de ciclo curto, como também em culturas perenes como bananeira, cafeeiro entre outras, Lopes et al. (2012), ao avaliarem o manejo ecológico dos produtores de café do sul de Minas Gerais, com o uso de matéria orgânica no solo, sendo roçada da de plantas daninhas e a palhada do próprio cafeeiro, identificaram que estes, obtiveram resultados positivos no manejo de pragas, além de resultados positivos na produção cafeeira.

Neste cenário, a biofumigação com uso de folhas de plantas da Região Amazônica, torna-se uma alternativa no manejo sustentável do nematoide-das-galhas do cafeeiro. Assim, nesse sentido, Desta forma, objetivou-se neste trabalho a avaliação da incorporação de folhas de Copaifera sp. e Vismia guianensis para o controle do Meloidogyne incognita em mudas clonais de Coffea Canephora.

\section{MATERIAIS E MÉTODOS}

\section{Local do experimento}

O presente trabalho foi realizado na Casa de Vegetação e Laboratório de Fitopatologia da Embrapa Rondônia, localizada na Rodovia BR-364, Km 5,5, Zona Rural, Porto Velho/RO. 


\section{Obtenção e preparo do inóculo de Meloidogyne incognita}

Os inóculos do nematoide utilizado nos ensaios foram obtidos de populações coletadas no Campo experimental da Embrapa em Ouro Preto do Oeste. Estas populações foram identificadas através de eletroforese, utilizando o método de Carneiro et al. (2001) e multiplicadas em plantas de tomateiro 'Santa Cruz Kada', mantidas em casa de vegetação. Para a extração dos ovos dos nematoides, foi utilizado o método de Hussey et al. (1973), modificado por Bonetti et al. (1981). Para tanto, as raízes foram trituradas em liquidificador em solução de hipoclorito $0,5 \%$ em água de torneira e o triturado foi peneirado em peneiras de 25, 400 e 500 mesh. Do que ficou retido na última peneira, se obteve a suspensão de ovos e juvenis de segundo estádio (J2).

\section{Obtenção das mudas para manutenção populacional do inóculo}

Para obtenção das mudas para manutenção populacional do inóculo, sementes de hortaliças foram semeadas em bandejas de isopor, com substrato comercial. As mudas com idade de 30 dias foram transplantadas para vasos de polipropileno com capacidade para 8,0 litros, com substrato preparado 1:1:1, sendo solo, areia e vermiculita. A metodologia de extração do inóculo foi descrito conforme tópico 2.2.

\section{Obtenção das plantas utilizadas na biofumigação}

Foram utilizadas folhas das plantas Copaifera sp. (copaiba) e Vismia guianensis (lacre vermelho), que foram coletadas no campo experimental da Embrapa-Rondônia. As coletas foram realizadas após aprovação no SisGen, e registradas sob o código de acesso ${ }^{\circ} A 7126 B 3$. Estas foram realizadas no período de julho a agosto de 2018, dentro do Campo Experimental da Embrapa Rondônia em Porto Velho nas coordenadas geográficas ( $8^{\circ} 53^{` 2} 20^{`}$ de latitude Sul e 63 06`40` de longitude Oeste de Grw). E os ensaios foram realizados dentro das Casas de Vegetação e laboratórios da Embrapa Rondônia, localizada no município de Porto Velho, RO.

\section{Biofumigação com Coffea canephora, clone 125}

As mudas de cafeeiro foram obtidas do centro experimental da Embrapa/RO, campus Ouro Preto do Oeste. Sendo mantidas em viveiro até 120 dias de idade, em substrato comercial, com irrigação constante de $6 \mathrm{~mm}$ de água por dia, com adubação foliar aplicada semanalmente. Foi utilizado o clone 125 de Coffea canephora, pertencente ao Banco de Germoplasma da Embrapa Rondônia.

Foi realizado a extração do Meloidogyne conforme metodologia citada no tópico 'obtenção e preparo do inóculo do Meloidogyne incognita', sendo inoculado 5.000 ovos por muda do cafeeiro. Para facilitar a infecção dos nematoides nas raízes, antes da inoculação foi realizada uma perfuração de aproximadamente $3 \mathrm{~cm}$ no substrato próximo a base de cada planta com auxílio de um bastão de vidro, local onde foi pipetada a suspenção. 
Neste ensaio foram utilizadas folhas trituradas de Copaifera sp. e V. guianensis, Estas foram divididas em material vegetal seco e fresco. Para o tratamento seco, após a coleta em campo, as folhas foram secas em estufa por três dias a $60^{\circ} \mathrm{C}$, após o processo de secagem, estas foram trituradas em moinho de facas e incorporadas ao solo. Para os tratamentos frescos, as plantas foram coletadas, trituradas e foram incorporadas ao solo. Esta incorporação foi feita proporção de 1:10 (material vegetal: solo, em um e 15 dias antes do plantio das mudas de cafeeiro. Foram utilizados como testemunha o nematicida de princípio ativo Carbofuran, na dose comercial (20mL/litro), o controle químico foi aplicado somente no momento do transplantio das mudas, conforme recomendações agronômicas do fabricante e as testemunhas sem material vegetal: inoculado e sem inoculação. Após 120 dias da inoculação, foi avaliado parâmetros nematológicos: fator de reprodução, obtido pela fórmula (FR=Pf /Pi), número de ovos/grama de raiz, o número total de ovos/muda, e o número de galhas/grama de raiz e fator agronômico, sendo estes: peso da matéria fresca da parte aérea e raízes.

\section{Delineamento experimental}

O experimento foi conduzido em delineamento do tipo Inteiramente Casualizado com seis repetições, sendo parcela experimental representada por um vaso, contendo uma muda do clone 125 . Os dados foram submetidos à análise de variância e as médias obtidas foram comparadas por teste de médias de Scott-Knott à $5 \%$ de significância.

\section{RESULTADOS E DISCUSSÃO}

A partir do ensaio realizado sob condições descritas anteriormente, é possível afirmar que, o tratamento de Copaifera sp., no qual as folhas foram incorporadas 15 antes fresco ao substrato, apresentou redução significativa para o parâmetro número de galhas por grama de raiz, diferindo dos demais tratamentos. Todavia vale destacar que os tratamentos de folhas do Vismia guianensis incorporados nos tempos $1 \mathrm{dia} / \mathrm{seco}, 15 \mathrm{dias} / \mathrm{seco}$ e 15 dias/fresco, além do Copaifera 15 dias/seco, diferiram do resultado obtido pelo nematicida carbofuran, obtendo um menor №G/gR (Figura 1).

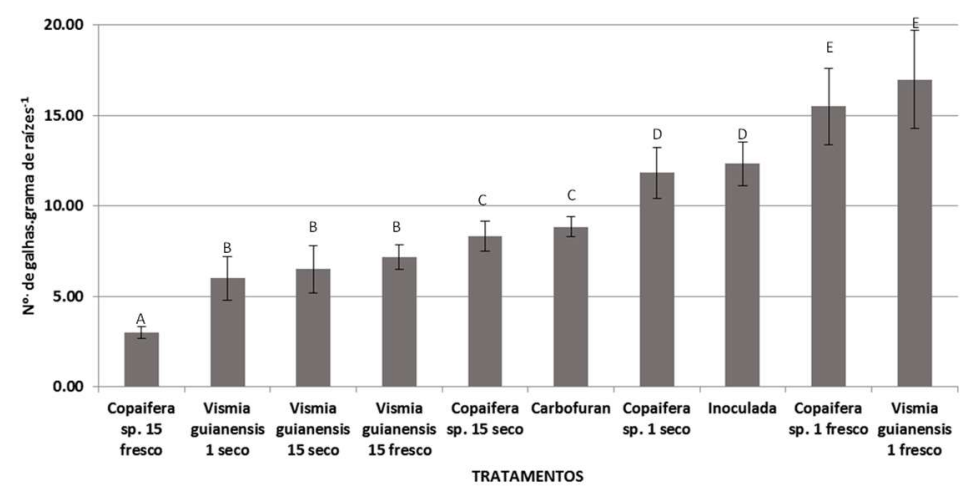

Figura 1: Número de galhas de M. incognita por grama de raiz de mudas de Coffea canephora, (clone 125) inoculada com 5.000 ovos. Médias seguidas pelas mesmas letras, constituem grupo estatisticamente homogêneo pelo teste de Scott-Knott a $5 \%$. 
A redução no número de galhas é um resultado interessante, pois a presença das mesmas nas raízes no sistema, privam o cafeeiro da absorção de água e nutrientes necessários ao seu desenvolvimento, interferindo no desenvolvimento e consequentemente na produção. Resultados similares ao descrito acima, foram observado também por Dias-Arieira et al. (2015), que, ao testarem bokashi e torta de crambe, reduziram o número de ovos e galhas por grama de raiz.

Alguns compostos químicos que são liberados pelas plantas, os chamados compostos orgânicos voláteis, possui uma diversidade de substâncias presente nas espécies vegetais, que podem afetar a patogenicidade e a mobilidade do nematoide, pois pela dificuldade de locomoção, o nematoide fica impedido de procurar o sistema radicular da planta hospedeira e impedindo a formação de galhas, o que foi confirmado por Barros et al. (2014) ao testar Brassica juncea, Azadirachta indica, Canavalia ensiformis, Mucuna pruriens e Cajanus cajan frescos no controle do M. Incognita.

O mesmo foi comprovado por Silva et al. (2013) ao estudar os efeitos dos compostos orgânicos voláteis totalizando seis combinações diferentes, de acordo com o fabricante, que constituíram os tratamentos, sobre o M. Exigua em Coffea arabica que reduziram número de galhas, além de ter causado alterações em substâncias como alcaloides, fenóis, etc. nas raízes do cafeeiro.

No presente experimento apresentado se observou que os tratamentos frescos aplicados apenas 1 dia antes do não tiveram resultados satisfatórios de redução do número de galhas, o que talvez possa ser explicado pelo fato de que esses materiais vegetais terem sido incorporados frescos e comum prazo menor para decomposição da matéria orgânica das folhas e liberação dos compostos. E possivelmente, isso por ter interferido na concentração final já que parte do peso aplicado por ter sido registrado sem levar em conta a água, pois os tratamentos divididos em material vegetal seco em estufa de circulação fechada, elimina o peso da umidade presente nessas folhas, além do tempo reduzido para sua decomposição e esses apresentaram efeito mesmo um dia antes.

Ao comparar os efeitos dos materiais vegetais secos e frescos na incorporação ao solo e seu efeito nematicida ao liberar os compostos presentes nas plantas, e ao procurar trabalhos que comparem a incorporação de materiais vegetais, foi observado que os testes são realizados com algumas espécies vegetais, porém sem testar a variável seco e fresco, em que Gardiano et al. (2013), testou somente seis espécies de inverno e onze espécies de verão secas em estufa, e Barros et al. (2014) testou macerados de folhas frescas de mostarda crespa (Brassica juncea) e neem (Azadirachta indica).

Ao relacionar o efeito das mesmas espécies na variável fresca e seca, como foi feito neste experimento, e seu efeito no controle de fitonematoides, foi testada por Alcântara Neto et al. (2018), dois experimentos, em que cada um possuía quatro concentrações, divididos em material fresco e seco da Tithonia diversiflora, e apesar do pesquisador ter testado somente doses e não tempo de decomposição da espécie, os resultados comprovam o efeito nematicida superior as características avaliadas, em todas as concentrações dessa espécie após o processo de secagem em comparação ao material fresco, o autor reforça 
a atividade nematicida de T. Diversifolia, pode ter sido intensificada pelo processo de decomposição que libera possíveis aleloquímicos.

No que tange ao efeito da incorporação das folhas na redução de ovos por grama de raiz, todos os tratamentos apresentaram potencial ovicida, principalmente o tratamento com Vismia guianensis 15 dias/seco, se destacando no controle deste parâmetro. Desses, os tratamentos Copaifera 1 dia/fresco e 15 dias/seco, também apresentaram potencial ovicida superior à testemunha carbofuran (Figura 2).

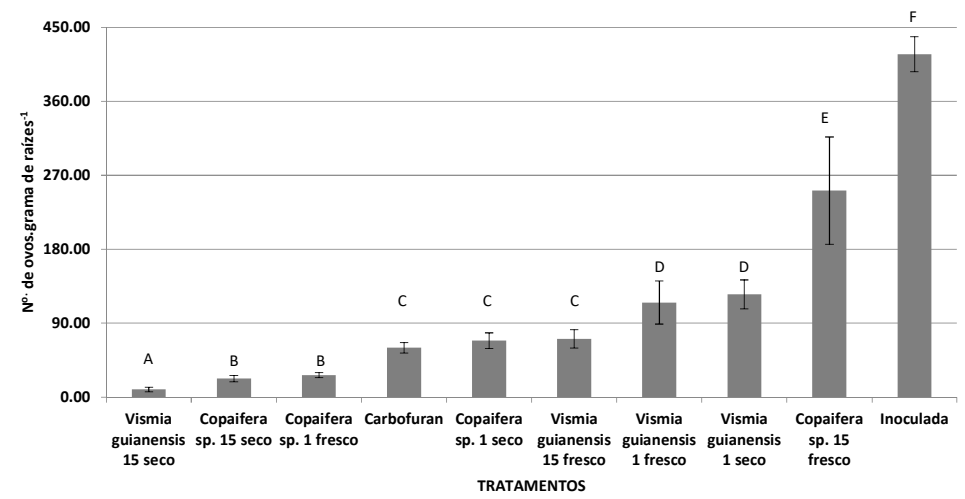

Figura 2: Número de ovos de M. incognita por grama de raiz de mudas de Coffea canephora, (clone 125) inoculada com 5.000 ovos. Médias seguidas pelas mesmas letras, constituem grupo estatisticamente homogêneo pelo teste de Scott-Knott a $5 \%$.

É interessante observar que os tratamentos Copaifera $1 \mathrm{dia} /$ fresco e Vismia guianensis $1 \mathrm{dia} /$ fresco, apesar de resultado em maior número de galhas, apresentaram valores inferiores no número de ovos por grama de raízes, com destaque ao Copaifera 1 dia/fresco, com resultado inferior ao carbofuran. Essa discordância também foi notada por Dias-Arieira et al., (2010), em que o resultado do tratamento de efluente de repolho+mostarda concentrado, apesar de ter um resultado superior em número de galhas, apresentou menor número de ovos, a autora afirma que esses resultados podem se dar possivelmente devido a variável número de fêmeas que pode ocorrer no interior das galhas. No fator reprodução o tratamento Vismia guianensis 15 dias/seco apresentou resultado zero neste parâmetro, comprovando sua eficácia na mortalidade de ovos e na multiplicação do patógeno no substrato (Figura 3).

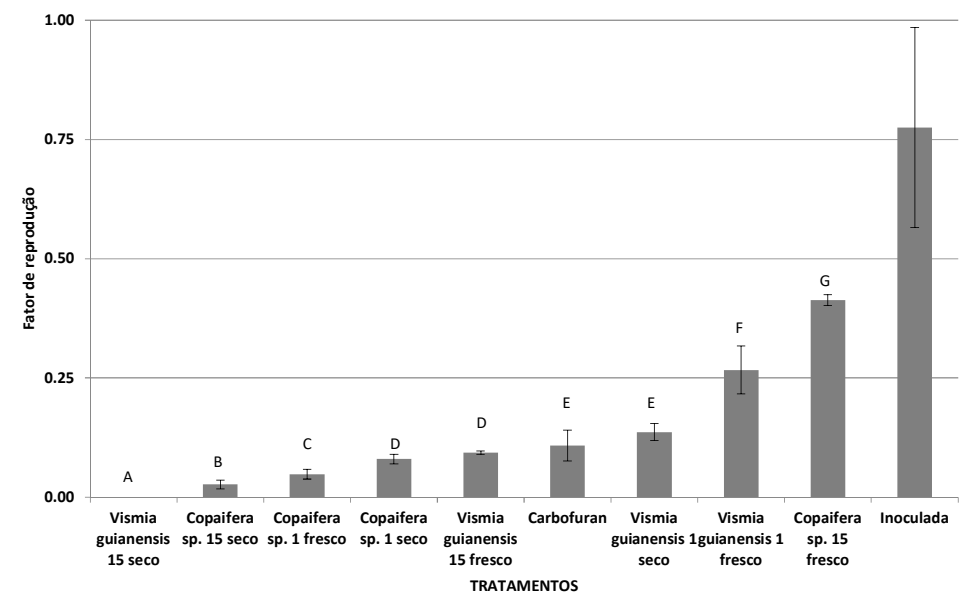

Figura 3: Fator de Reprodução do Meloidogyne incognita, em Coffea canephora, c. 125 inoculada com 5.000 ovos. Médias seguidas pelas mesmas letras, constituem grupo estatisticamente homogêneo pelo teste de Scott-Knott a $5 \%$. 
O Azidiractha indica, mais popularmente conhecido como neem, foi testado incoporado ao solo, e/ ou isoladamente com estrume animal, e Auwal et al. (2015), relatou que o tratamento de neem+estrume não diferiu do controle químico (furadan), todavia todos os tratamentos, apresentaram menor fator de reprodução que o controle. $O$ mesmo foi observado no experimento com objetivo de testar o antagonismo de Java (leguminosa), em que obteve Fator reprodução do $M$. Incognita menor que 1 , que demonstra a caracteristica nematicida dessa espécie (MIAMOTO et al., 2018).

Vale salientar que todos os tratamentos testados, apresentaram valor no Fator reprodução menor que 1 , o que confere com Santos et al. (2017), que identificou FR de 0,20 , no clone 125, o mesmo usado no presente experimento. $O$ processo de parasitismo do nematoide-das-galhas sobre o cafeeiro resulta, entre outras coisas, em mudas comprometidas quanto ao seu desenvolvimento vegetativo, mas ao incorporar os material vegetais dos oito tratamentos a seres testados, observou-se que as mudas de Coffea canephora apresentaram peso da matéria seca das raízes inferior as três testemunhas testadas, e os tratamentos Vismia guianensis 1 dia/fresco e Copaifera sp. 1 e 15 dias fresco não diferiram das testemunhas (Figura 4).

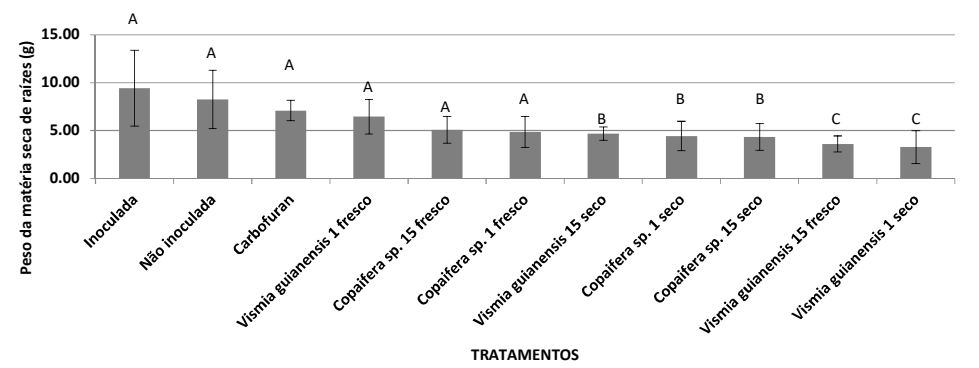

Figura 4: Peso da matéria seca das raízes de Coffea canephora, c. 125 inoculada com 5.000 ovos do M. incognita. Médias seguidas pelas mesmas letras, constituem grupo estatisticamente homogêneo pelo teste de Scott-Knott a 5\%.

Esses resultados demonstram que a incorporação não incrementou o peso da materia seca da parte aérea, como é relatado positivamente em diversos trabalhos (NEVES et al., 2011; MACHADO et al., 2013; DANEEL et al., 2018), porém estes resultados foram obtidos em hortaliças, que são alvos dos experimentos com agricultura orgânica, pois são geralmente consumidos in natura.

Esses resultados demonstram que a incorporação não incrementou o peso da materia seca da parte aérea, como é relatado positivamente em diversos trabalhos (NEVES et al., 2012; MACHADO et al., 2013; DANEEL et al., 2018). Há que se ressaltar que as respostas em plantas anuais tende a serem demonstradas mais rapidamente que plantas perenes, especiamente pelo fato de estarem mantidas em vasos e em casa de vegetação, onde as condições para o crescimento certamente são sub-ótimas, especialmente para plantas que são tipicamente de sol pelo, como o cafeeiro 'canephora'.

No peso da máteria seca da parte aérea, somente três tratamentos apresentaram maior peso, porém não diferiram das três testemunhas testadas, os outros cinco tratamentos apresentaram menor peso da parte aérea do cafeeiro conforme figura 5. A vantagem do uso da incorporação de material vegetal, foi identificada por Atandi et al. (2017) ao comparar resultados do solo com incorporação do composto de Tithonia diversiflora e neem em comparação com a agricultura convencional, que utiliza fertilizante e 
nematicida, afirmando assim que a agricultura orgânica pode ser uma alternativa viável a dependência de produtos químicos.

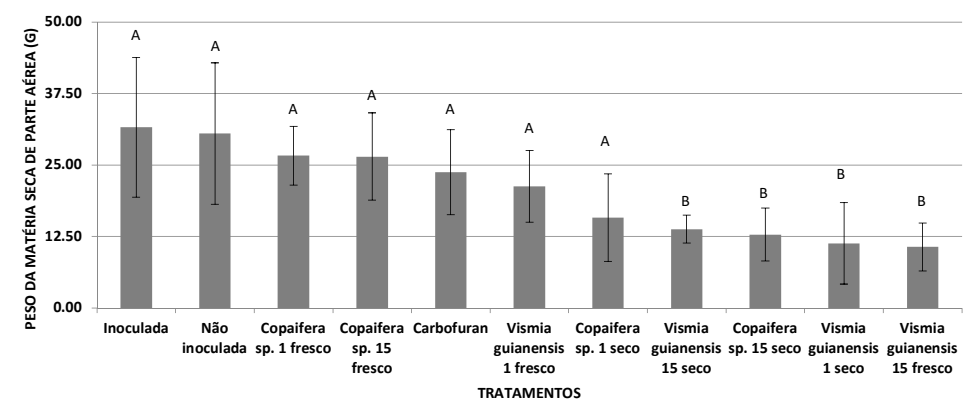

Figura 5: Peso da matéria seca da parte aérea de Coffea canephora, c. 125 inoculada com 5.000 ovos do M. incognita. Médias seguidas pelas mesmas letras, constituem grupo estatisticamente homogêneo pelo teste de Scott-Knott a 5\%.

Lopes et al. (2012) afirma que a produtividade média nos sistemas organo-mineral e orgânico obtiveram uma produtividade superior ao sistema convencional, além do controle de pragas e doenças em cafeeiros de Minas Gerais. O mesmo observado por Silva et al. (2013), que ressalta o potencial dos compostos orgânicos como uma alternativa de melhorar as características de fertilidade do solo em sistemas de café conilon no Espírito Santo, estado esse maior produtor da espécie, comprovando assim que o uso de adubação verde e/ ou incorporação de matéria orgânica pode ser utilizada não somente em culturas de ciclo curto, como em perenes, no caso o cafeeiro.

Porém pesquisas por novas plantas existentes na região, que possam ser testadas, visando descobrir novos compostos químicos, com efeito nematicida, além de melhorar a fertilidade do substrato usado, tornase uma possibilidade no manejo cafeeiro, todavia são poucos os artigos que evidenciam o uso da incorporação de espécies vegetais em Coffea canephora, no entanto os resultados encontrados neste experiemento com uso de Copaifera sp. e Vismia guianensis, além dos autores citados acima, comprova que esse controle alternativo pode ser utilizado no controle da doença em mudas do cafeeiro, considerando a disponibilidade e da diversidade de espécies presentes que podem ser investigadas quanto ao seu potencial.

\section{CONCLUSÕES}

Com base nos resultados apresentados, conclui-se que o tratamento $V$. guianensis 15 seco apresentou resultados significativos no №Og/R e FR, podendo ser usado no manejo de nematoides em substratos.

AGRADECIMENTO: Este estudo foi apoiado pelo Conselho Nacional de Desenvolvimento Científico e Tecnológico (CNPq) através do projeto para CFF - Número do subsídio 485047/2013-6, Financiadora de Estudos e Projetos (FINEP), Fundação Rondônia de Amparo ao Desenvolvimento das Ações Científicas e Tecnológicas e de Pesquisa do Estado de Rondônia (FAPERO), através do projeto para No.033/2017 (termo de outorga 01.1331.00033-00.033/2017) e Consórcio Brasileiro de Pesquisa do Café - FUNAPE; por meio do 
Projeto SEG-Embrapa no.02.13.02.014.00. Os autores agradecem Domingos Sávio G. Silva e Antônio M.

Marques pela assistência técnica.

\section{REFERÊNCIAS}

ALCÂNTARA NETO, F.; DELPUPO, K. C.; SILVA, G. S.; GRAVINA, G. A.; MELO, M. P.; BESERRA JÚNIOR, J. E. A.. Folhas de girassol mexicano como alternativa no manejo de Pratylenchus brachyurus em quiabeiro. Summa Phytopathologica, Botucatu, v.44, n.3, p.267-270, 2018. DOI: http://dx.doi.org/10.1590/0100-5405/169428

ALMEIDA, L. S.; GUIMARÃES, E. C.. Uso da geoestatística no manejo sustentável de nematoide das galhas do cafeeiro. Coffee Science, v.12, n.4, p.471-479, 2017.

ATANDI, J. G.; KAUKELAND, S.; KARIUKI, G. M.; COYNE, D. L.; KARANJA, E. N.; MUSYOKA, M. W.; FIABO, K. K. M.; BAUTZE, D.; ADAMTEY, D.. Organic farming provides improved management of plant parasitic nematodes in maize and bean cropping systems. Agriculture, Ecosystems and Environment, v.247, p.265-272, 2017. DOI: http://doi.org/10.1016/j.agee.2017.07.002

AUWAL, H. M.; GALADIMA, I. B.; MADU, J.; JOSEPH, P.. Evaluation of Synergistic Effect of Neem and Poultry Manure on Root Knot Nematode (Meloidogyne spp.) Infecting Rice. Open Access Library Journal, v.2, p.1372-1375, 2015. DOI: http://doi.org/10.4236/oalib.1101372

BARROS, A. F.; CAMPOS, V. P.; SILVA, J. C. P.; PEDROSO, M. P.; MEDEIROS, F. H. V.; POZZA, E. A.; REALE, A. L..

Nematicidal activity of volatile organic compounds emitted by Brassica juncea, Azadirachta indica, Canavalia ensiformis, Mucuna pruriens and Cajanus cajan against Meloidogyne incognita. Applied Soil Ecology, v.80, p.34-43, 2014. DOI: http://doi.org/10.1016/j.apsoil.2014.02.011

BARROS, A. F.; CAMPOS, V. P.; SILVA, J. C. P.; LÓPEZ, L. E.; SILVA, A. P.; POZZA, E. A.; PEDROSO, L. A.. Tempo de exposição de juvenis de segundo estádio a voláteis emitidos por macerados de nim e de mostarda e biofumigação contra Meloidogyne incognita. Nematropica, v.44, n.2, p.190-199, 2014.

BONETTI, J. I. S.; FERRAZ, S.. Modificação do método de Hussey \& Barker para extração de ovos de Meloidogyne exigua de raízes de cafeeiro. Fitopatologia Brasileira, v.6, n.3, p.553, 1981.

CARNEIRO, R. M. D. G.; RANDING, O.; ALMEIDA, M. R. A.; GONÇALVES, W.. Identificação e Caracterização de Espécies de Meloidogyne em Cafeeiro nos Estados de São Paulo e Minas Gerais, Através dos Fenótipos de Esterase e SCARMultiplex- PCR. Nematologia Brasileira, v.29, n.2, p.233-241, 2005.

CONAB. Companhia Nacional de Abastecimento. Acompanhamento da safra brasileira, Primeiro levantamento. Brasília: CONAB, 2018.

D'ADDABBO, T.; ARGENTIEIRI, M. P.; RADICCI, V.; GRASSI, F.; AVATO, P.. Artemisia annua compounds have potential to manage root-knot and potato cyst nematodes. Crop
Protection, v.80, p.21-41, 2016. DOI:

http://doi.org/10.1016/i.indcrop.2017.06.025

DANEEL, M.; ENGELBRECHT, E.; FOURIE, H.; AHUJA, P.. The host status of Brassicaceae to Meloidogyne and their effects as cover and biofumigant crops on root-knot nematode populations associated with potato and tomato under South African field conditions. Crop Protection, v.110, p.198-206, 2018. DOI: http://doi.org/10.1016/j.cropro.2017.09.001

DIAS-ARIEIRA, C. R.; MATTOS, R. M.; SASSAKI, T. C.; PUERARI, H. H.; CUNHA, T. P. L.; BIELA, F.; CHIAMOLERA, F. M.. Manejo de Meloidogyne incognita Utilizando Efluentes de Biodigestor à Base de Repolho, Mostarda, Alho e Pimenta. Nematologia Brasileira, v.3, n.2, p.143-149, 2010.

DIAS-ARIEIRA, C. R.; MATTEI, D.; PUERARI, H. H.; RIBEIRO, R. C. F.. Use of organic amendments in the management of root-knot nematode in lettuce. Horticultura Brasileira, v.33, p.488-492, 2015

ESTUPINÃN-LÓPEZ, L.; CAMPOS, V. P.; SILVA, A. P.; BARROS, A. F.; PEDROSO, M. P.; SILVA, J. C. P.; TERRA, W. C.. Volatile organic compounds from cottonseed meal are toxic to Meloidogyne incognita. Tropical Plant Pathology, v.42, p.443-450, 2017.

FARINA, R.; TESTANI, E.; CAMPANELLI, G.; LETEO, F.; NAPOLI, R.; CANALI, S.; TITTARELLI, F.. Potential carbon sequestration in a Mediterranean organic vegetable cropping system. A model approach for evaluating the effects of compost and Agro-ecological Service Crops (ASCs). Agricultural Systems, v.162, p.239-248, 2018. DOI:

http://doi.org/10.1016/i.agsy.2018.02.002

GARDIANO, C. G.; KRZYANOWKI, A. A.; SAAB, O. J. A.; DALLEMOLE-GIARETTA, R.; LOPES, E. A.. Redução populacional do nematoide reniforme com a incorporação de plantas de cobertura ao solo em casa de vegetação. Nematropica, v.43, n.1, p.138-142, 2013.

GONÇALVES, A. C. R.; MIRANDA, O. N. S.; ARAÚJO, L. L. N.. Prospecção fitoquímica das folhas de Copaifera langsdorffii pertencente à família Leguminosae. Revista Fasem Ciências, v.9, n.1, p.37-54, 2016.

HANDISENI, M.; CROMWELL, W.; ZIDEK, M.; ZHOU, X.; JO, Y.. Use of brassicaceous seed meal extracts for managing rootknot nematode in Bermudagrass. Nematropica, v.47, n.1, 2017.

HMIMOU, A.; MASLOUHI, A.; TAMOH, K.; CANDELA, L. Experimental monitoring and numerical study of pesticide (carbofuran) transfer in an agricultural soil at a field site. Comptes Rendus Geoscience, v.346, p.255-261, 2014. DOI: http://doi.org/10.1016/i.crte.2014.03.003

HUSSEY, R. S.; BARKER, K. R.. A comparison of methods for collecting inocula of Meloidogyne spp., including a new 
technique. Plant Disease Reporter, v.57, n.12, p.1025-1028, 1973.

JARDINE, K. J.; JARDINE, A. B.; SOUZA, V. F.; CARNEIRO, V.; CERON, J. V.; GIMENEZ, B. O.; SOARES, C. P.; DURGANTE, F. M.; HIGUCHI, N.; MANZI, A. O.; GONÇALVES, J. F. C.; GARCIA, S.; MARTIN, S. T.; ZORZANELLI, R. F.; PIVA, L. R.; CHAMBERS, J. Q.. Methanol and isoprene emissions from the fast growing tropical pioneer species Vismia guianensis (Aubl.) Pers. (Hypericaceae) in the central Amazon forest. Atmospheric Chemistry and Physics, v.16, p.6441-6452, 2016. DOI: http://doi.org/10.5194/acp-16-6441-2016

LOPES, P. R.; ARAÚJO, K. C. S.; FERRAZ, J. M. G.; LOPES, I. M.; FERNANDES, I. G.. Produção de café agroecológico no sul de Minas Gerais: sistemas alternativos à produção intensiva em agroquímicos. Revista Brasileira de Agroecologia, v.7, n.1, p.25-38, 2012.

MACHADO, J. C.; VIEIRA, B. S.; LOPES, E. A.; CANEDO, E. J.. Controle de meloidogyne javanica com Pochonia chlamydosporia E ESTERCO BOVINO. Bioscience Journal, v.29, n.3, p.590-596, 2013.

MIAMOTO, A.; DIAS-ARIEIRA, C. R.; PUERARI, H. H.; MIORANZA, T. M.; PEREIRA, C. B.. Antagonistic Effects of Java against Plant Parasitic Nematodes. Journal of Agricultural Science, v.10, n.2, 2018. DOI: http://doi.org/10.5539/jas.v10n2p289

NEVES, W.S.; FREITAS, L. G.; DALLEMOLE-GIARETTA, R.; COUTINHO, M. M.; FERRAZ, S.; PARREIRA, D. F.. Incorporação de Farinha de Semente de Mamão ao Solo para o Controle de Meloidogyne javanica. Nematologia Brasileira, v.36, n.1-2, p.25- 31, 2012.

OLIVEIRA, C. M. G.; ROSA, J. M. O.. Boletim Técnico: Nematoides Parasitos do Cafeeiro. 2018.

PEREIRA, N. C. M.; MARISCAL, A. G.; NEPOCENO, K. L. P.; SILVA, V.C. C. R.; FERNANDES, H. M.; VIVI, V. K.. Atividade antimicrobiana do óleo-resina de copaíba natural/comercial contra cepas padrão. Journal Health NPEPS, v.3, n.2, p.527539, 2018.

RIFEEL, A.; COSTA, J. G.. Os Voláteis de Plantas e o seu Potencial para a Agricultura. Aracaju: Embrapa Tabuleiros Costeiros, 2015.

SANTOS, J. L.; LEITE, O. D.. Avaliação do Risco de Contaminação de Águas Subterrâneas na Região Oeste da Bahia pelo Inseticida Carbofuran, Empregando os Modelos Attenuation Factor (AF) e Retardation Factor (RF). Orbital: The Electronic Journal of Chemistry, v.8, n.1, p.28-35, 2016. DOI: http://doi.org/10.17807/orbital.v1i1.715

SANTOS, A. C. V.; FERNANDES, C. C.; LOPES, L. M.; SOUSA, A. $\mathrm{H}$.. Inseticidal oils from amazon plants in control of fall armyworm. Revista Caatinga, v.29, n.3, p.642-647, 2016.

SANTOS, A. V.; ROCHA, R. B.; FERNANDES. C. F.; SILVEIRA, S. F.; RAMALHO, A. R.; VIEIRA JÚNIOR, J. R.. Reaction of Coffea canephora clones to the root knot nematode, Meloidogyne incognita. African Journal, v.12, n.11, p.916-922, 2017.

SILVA, V. M.; TEIXEIRA, A. F. R.; REIS, E. F.; BENASSI, A. C.; MENDONÇA, E. S.. Atributos químicos do solo em sistemas de adubação orgânica de café conilon. Coffee Science, v.8, n.4, p.469-477, 2013.

SILVA, W. R. J.; MACHADO, A. R. T.; CAMPOS, V. A. C.; ZERI, A. C. M.; CAMPOS, V. P.; OLIVEIRA, D. F.. Volatile organic compounds for the control of Meloidogyne exigua in Coffea arabica. Tropical Plant Pathology, v.38, n.5, p.375-386, 2013. DOI: http://dx.doi.org/10.1590/S19825676201300050000

VIEIRA JUNIOR, J. R.; FERNANDES, C. F.; MATOS, S. I.; FREIRE, T. C.; FONSECA, A. S.; MARREIROS, J. A. A.; ZEFERINO, D. M.; SILVA, D. S. G.. Levantamento da ocorrência de populações do nematoide-das-galhas-do-cafeeiro (Meloidogyne sp.) em Rondônia: primeira atualização. Porto Velho: Embrapa, 2015.

A CBPC - Companhia Brasileira de Produção Científica (CNPJ: 11.221.422/0001-03) detém os direitos materiais desta publicação. Os direitos referem-se à publicação do trabalho em qualquer parte do mundo, incluindo os direitos às renovações, expansões e disseminações da contribuição, bem como outros direitos subsidiários. Todos os trabalhos publicados eletronicamente poderão posteriormente ser publicados em coletâneas impressas sob coordenação da Sustenere Publishing, da Companhia Brasileira de Produção Científica e seus parceiros autorizados. Os (as) autores (as) preservam os direitos autorais, mas não têm permissão para a publicação da contribuição em outro meio, impresso ou digital, em português ou em tradução. 